\title{
An agmatine-inducible system for the expression of recombinant proteins in Enterococcus faecalis
}

\author{
Daniel M Linares, Marta Perez, Victor Ladero, Beatriz del Rio, Begoña Redruello, Ma Cruz Martin, \\ María Fernandez ${ }^{*}$ and Miguel A Alvarez
}

\begin{abstract}
Background: Scientific interest in Enterococcus faecalis has increased greatly over recent decades. Some strains are involved in food fermentation and offer health benefits, whereas others are vancomycin-resistant and cause infections that are difficult to treat. The limited availability of vectors able to express cloned genes efficiently in $E$. faecalis has hindered biotechnological studies on the bacterium's regulatory and pathogenicity-related genes. The agmatine deiminase (AGDI) pathway of $E$. faecalis, involved in the conversion of agmatine into putrescine, is driven by a response inducer gene aguR.

Results: This study describes that the exposure to the induction factor (agmatine) results in the transcription of genes under the control of the aguB promoter, including the aguBDAC operon. A novel E. faecalis expression vector, named pAGEnt, combining the aguR inducer gene and the aguB promoter followed by a cloning site and a stop codon was constructed. pAGEnt was designed for the overexpression and purification of a protein fused to a 10-amino-acid His-tag at the C-terminus. The use of GFP as a reporter of gene expression in E. faecalis revealed that under induction with $60 \mathrm{mM}$ agmatine, fluorescence reached 40 arbitrary units compared to 0 in uninduced cells.

Conclusion: pAGEnt vector can be used for the overexpression of recombinant proteins under the induction of agmatine in E. faecalis, with a close correlation between agmatine concentration and fluorescence when GFP was used as reporter.
\end{abstract}

Keywords: Enterococcus, Overexpression, Expression vector, Agmatine

\section{Background}

Members of the genus Enterococcus are found throughout the normal gut of vertebrates and insects and are commonly associated with fermented foods. In artisanal Mediterranean cheeses they are believed important in the development of flavour and aroma [1-3]. Enterococcus has been the subject of much research given its members' potential as biopreservatives. Some strains isolated from cheese produce enterocins (bacteriocins); their bactericidal activity may be effective against foodborne pathogens such as Listeria monocytogenes, Vibrio cholerae, Staphylococcus aureus, Clostridium botulinum, Salmonella enterica and Bacillus cereus, as well as against spoilage microorganisms [4-8]. Indeed, non-pathogenic enterococci have promising commercial potential [9].

\footnotetext{
* Correspondence: mfernandez@ipla.csic.es

Instituto de Productos Lácteos de Asturias, IPLA-CSIC, Paseo Río Linares s/n, 33300 Villaviciosa, Asturias, Spain
}

They are already used as starter cultures in certain artisanal food fermentations and are commercially available as probiotics [10-12]. For example, Enterococcus faecalis Symbioflor 1 clone DSM 16431 is included in a commercial probiotic product with potential benefits for human health - it has been used for over 50 years with no reports of infection [13]. Given their ability to improve the microbial equilibrium of the intestine, some strains of Enterococcus faecium have also been used as probiotic adjunct cultures in the making of Cheddar cheese [7]. In addition, enterococci have been used as animal feed additives in the European Union [14], and as probiotics for farm animals destined for human consumption [15-17]. The wellstudied probiotic strain E. faecium SF68, produced in Switzerland under the name Cylactin ${ }^{\circ}$ (DSM Nutritional Products Ltd.), is currently authorised by the European Food Safety Authority (EFSA) for use in goat and kid feed for the treatment of diarrhoea $[18,19]$. 
Enterococci can, however, also be harmful. Some strains have been studied because of their production of biogenic amines (mostly tyramine and putrescine) in fermented foods [20-23]. Other strains have virulence factors and are recognised as emerging pathogens responsible for serious clinical infections $[24,25]$. Enterococci are also among the most important multidrug-resistant organisms affecting immunocompromised patients [26]. This bacterial group can acquire genetic determinants that confer resistance to antibiotics and it is particularly concerning the acquisition of vancomycin resistance [27]. Indeed, the emergence of vancomycin-resistant enterococci (VRE) has alarmed the global infectious diseases community given the few options left for the management of their associated diseases. The transfer of resistance genes from enterococci to other strains, the presence of selection pressures for VRE proliferation, and the rapid expansion of resistant populations are matters of great concern. The prevalence of VRE has been reported for Europe, Asia, Australia, South America and some African countries [26].

Our knowledge of the regulation of virulence factors in E. faecalis, and of the environmental signals that contribute towards pathogenicity, remains poor [28]; a pressing need exists to understand this infectious agent at the genetic and physiological level. Studies in these areas, however, require molecular and genetic tools be available. For many investigations, e.g., on genetic regulation, knock-out complementation, the heterologous expression of bacteriocins in bacteriocin-negative hosts, or research on membrane permeases, the overexpression of genes is often required [29-31]. For Enterococcus, some expression vectors based on bacteriocin-inducible promoters have been developed, but these require the genes encoding the kinase and regulator proteins supplied in trans [32]. Beside this, the widely used Lactococcus lactis NICE system is suitable for use in other Gram-positive species including Enterococcus, either by using two simultaneous compatible plasmids - one harbouring the expression cassette and the other carrying the nisRK genes- [33], or as a single-plasmid expression vector including both cassettes [34]. In addition, other E. faecalis expression systems based on rhamnose as inducer [35] or under control of the pheromone cCF10 [36] have been described. Yet, the molecular genetic tools available for $E$. faecalis are more limited than for some other microorganisms. In recent years, research has therefore focused on the development of alternative Grampositive bacterial expression systems for the production of industrially important proteins [36]. The development of controlled gene expression systems for homologous and heterologous gene expression therefore remains an important goal.

The agmatine deiminase (AGDI) genes cluster of E. faecalis contains the genes necessary for the biosynthesis of putrescine from agmatine. aguD encodes for the agmatine/putrescine antiporter, aguA encodes for the agmatine deiminase, $a g u B$ encodes for the putrescine transcarbamylase, and aguC encodes for a specific carbamate kinase [22]. Overall, the locus is organized in an operon constituted by the metabolic genes aguB, aguD, $a g u A$ and $a g u C$, which are cotranscribed in a single mRNA from the $a g u B$ promoter $\left(\mathrm{P}_{a g u B}\right)$, in a divergent orientation with the putative regulator gene $(a g u R)$ that has its own promoter $\left(\mathrm{P}_{\text {aguR }}\right)$ [37] (Figure 1A). Our working hypothesis is that AguR would activate the transcription from $\mathrm{P}_{a g u B}$ and therefore, we could construct a genetic expression system inducible by the addition of agmatine in the culture medium.

In the present work, by combining the $a g u R$ inducer gene and the $\mathrm{P}_{\text {aguB }}$ promoter (with its natural ribosome binding site), a new agmatine-inducible expression system - the "agmatine controlled expression (ACE)" system - was developed. This system was successfully used in the production of green fluorescent protein (GFP) in E. faecalis V583, and offers a practical and straightforward method for the heterologous expression of other recombinant proteins in E. faecalis.

\section{Results}

\section{Influence of agmatine on putrescine production}

Since agmatine is the substrate for putrescine biosynthesis in the AGDI pathway, the potential of E. faecalis V583 to produce putrescine in GM17 supplemented with a range of different concentrations of agmatine $(0,0.05$, $0.1,0.25,0.5,1,5,10$ or $20 \mathrm{mM}$ ) was investigated. Liquid cultures were inoculated $(2 \% \mathrm{v} / \mathrm{v})$ with overnight cultures and incubated at $37^{\circ} \mathrm{C}$ for $24 \mathrm{~h}$. Accumulation of putrescine in the supernatants was analysed by UPLC ${ }^{\mathrm{m}}$ (Figure 1B). As expected, a positive correlation was seen between agmatine supplementation and putrescine accumulation in the extracellular medium. Putrescine was first detectable in the supernatant after treatment with $0.1 \mathrm{mM}$ agmatine. Above this concentration, putrescine accumulation was gradually increased with increasing agmatine concentration.

\section{Transcriptional regulation of the AGDI operon by agmatine}

The expression profile of the genes of the AGDI operon was analysed by RT-qPCR in GM17 media with supplementation of $0,0.05,0.1,0.25,0.5,1,5,10$ or $20 \mathrm{mM}$ agmatine. RNA samples were taken at the end of the exponential phase of growth $(t=6$ h; i.e., once putrescine production had started) and mRNA levels compared. Since $a g u B, a g u D, a g u A$ and $a g u C$ are coexpressed in a single transcript, the expression of $\operatorname{aguA}$ is shown as representative of all aguBDAC mRNA. 


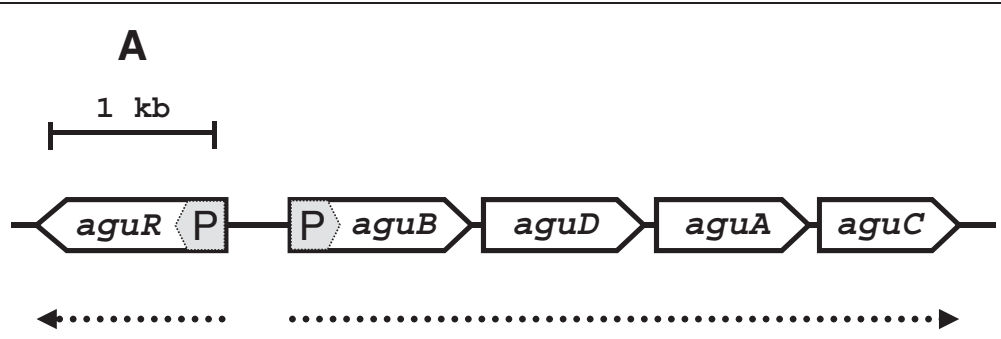

B

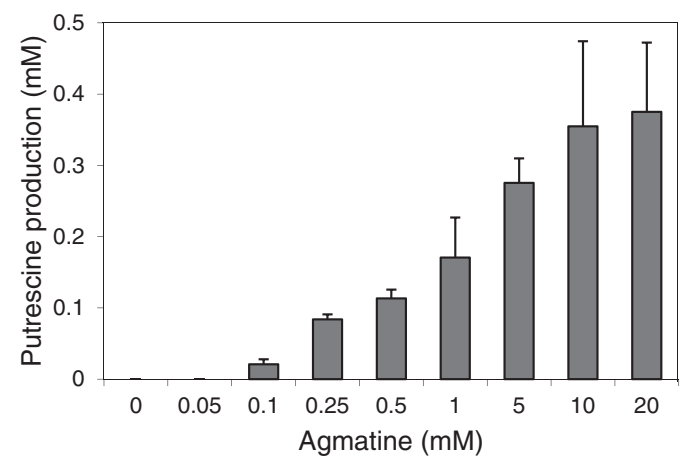

Figure 1 Genetic organization of the AGDI cluster of $E$. faecalis V583 and putrescine production. A. The AGDI cluster of $E$. faecalis is composed of five genes, aguR encoding a putative regulator, followed by aguB, aguD, aguA and aguC which encode the putrescine biosynthesis pathway (accession number NC_004668). The $P_{a q u R}$ and $P_{a q u B}$ promoters are shaded and their predicted transcripts are indicated below (dotted arrows). B. Putrescine production by E. faecalis V583 in $24 \mathrm{~h}$ cultures grown with $0,0.05,0.1,0.25,0.5,1,5,10$ or 20 mM agmatine. Values are the means of three independent assays and error bars denote standard deviation.

The expression level of aguR remained almost constant under all conditions of agmatine supplementation (Figure 2). However, the expression of aguBDAC was strictly dependent on agmatine, and a significant increase in aguBDAC mRNA was observed under agmatine supplementation. In fact, agmatine induction of aguR transcription (approximately 2 -fold increase in relative transcript levels) was much lower than that of the $a g u B$ $D A C$ operon (approximately 10,000-fold increase in relative transcript levels) (Figure 2).

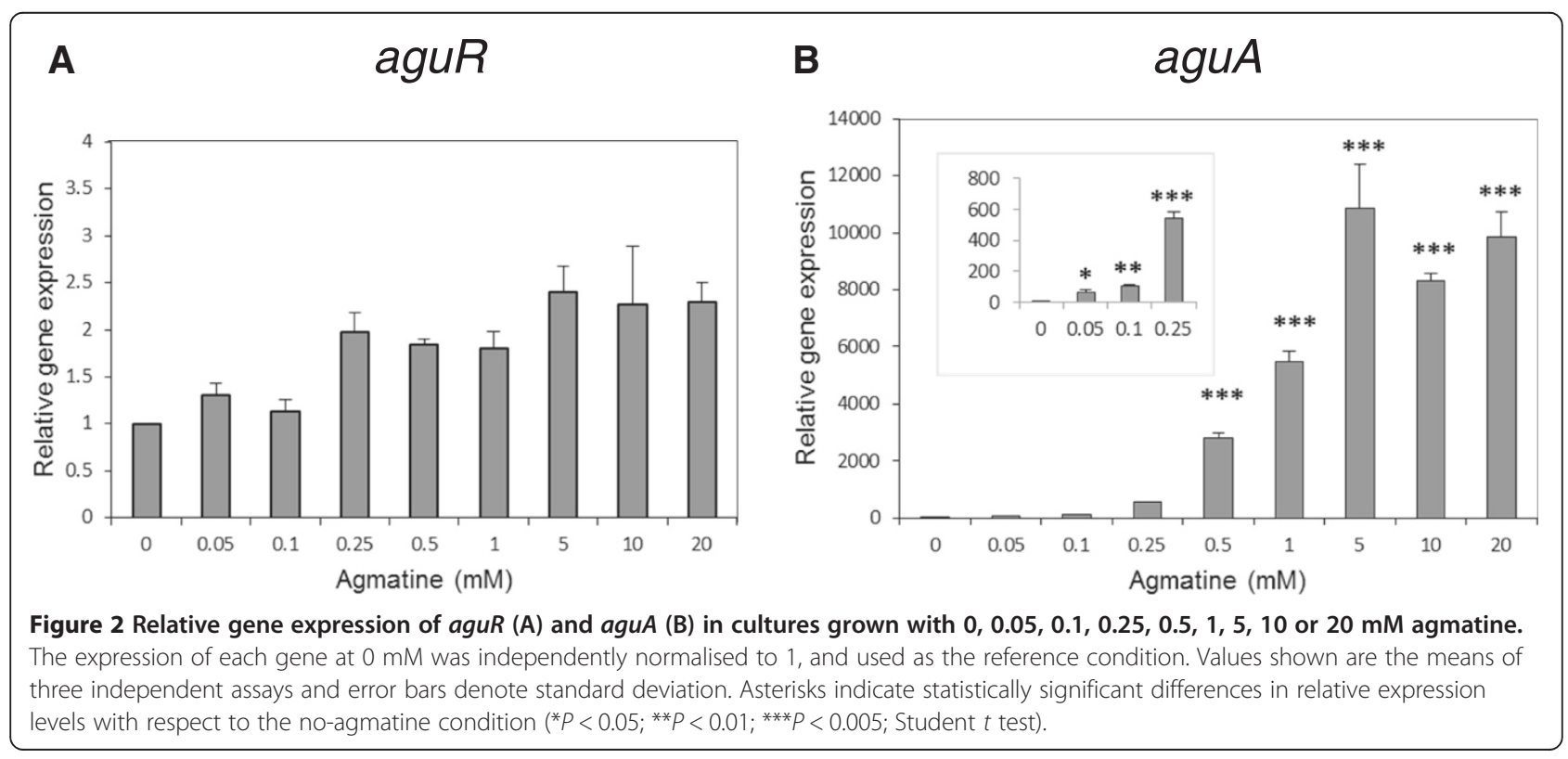




\section{Construction of the expression vector pAGEnt}

The core of the lactococcal vector pNZ8048 [38,39], which includes the replication cassette and the chloramphenicol resistance marker, was used as a starting point for the construction of the pAGEnt vector. First, a fragment of the chromosomal AGDI cluster from E. faecalis V583 including the aguR promoter $\left(\mathrm{P}_{\text {aguR }}\right)$, the aguR gene, and the $a g u B$ promoter $\left(\mathrm{P}_{a g u B}\right)$, was amplified by PCR using the primers indicated in Table 1 , and cloned into the BglII-NcoI sites of pNZ8048. A fragment including the multicloning site and the histidine tag (His-tag) sequence was then PCR-amplified using plasmid pNZErmC [40] as a template, employing the primers Expvfor1 and Expvrev1. The products were digested and cloned into the NcoI-HindIII sites of the previous vector, thus providing plasmid pAGEnt (Figure 3).

The resulting pAGEnt vector offers the possibility of traditional cloning without the His-tag, i.e., the insertion of the gene of interest into the extensive range of sites provided by the multiple cloning site, or the fusion of an optional C-terminal 10x His-Tag by cloning the target gene specifically into the NcoI-PstI sites. The latter alternative enables the insertion of a promoterless gene into the correct frame, fused to the His-tag and ready for expression. Subsequent protein purification is therefore possible. Thus, this vector can be used for gene overexpression, protein immunodetection, and purification purposes.

\section{Controlled heterologous expression of $g f p$}

To test the usefulness of pAGEnt in the expression of a foreign gene, tests were performed to determine whether the aguR $/ \mathrm{P}_{\text {aguB }}$ cassette was able to drive the expression of heterologous genes. The promoterless gene $g f p$ encoding green fluorescent protein was cloned (using the primers indicated in Table 1) as a reporter into the NcoIPstI sites of pAGEnt, generating the vector pAGEnt-GFP. Fluorescence measurements revealed that, upon the addition of the induction factor agmatine $(20 \mathrm{mM})$, AguR significantly enhanced the expression of $g f p$ by up to 10.13 arbitrary units. Parallel cultures harbouring the empty vector pAGEnt, or the vector pAGEnt-GFP with no agmatine present, provided negative controls; expression of the gene of interest was undetectable ( $<0.5$ arbitrary units).

\section{Sensitivity of the pAGEnt system to the inducer: dose-response curve}

The control afforded by the agmatine-induced expression system in the production of recombinant proteins was tested. The production of GFP in cultures, induced with a range of agmatine concentrations (between 0 and $60 \mathrm{mM}$ ), was analysed by whole-cell fluorescence. Figure 4 shows an increase in fluorescence with even low concentrations of agmatine $(1 \mathrm{mM})$. Induction levels increased with the agmatine concentration; indeed, a close correlation was seen between agmatine concentration and fluorescence $\left(R^{2}=0.979\right)$. In the presence of $60 \mathrm{mM}$ agmatine, fluorescence reached 40 arbitrary units compared to 0 in uninduced cells. The virtual lack of fluorescence with $0 \mathrm{mM}$ agmatine demonstrates the absence of any leaky activity of the promoter $\mathrm{P}_{a g u B}$.

\section{Toxicological assessment of agmatine in Enterococcus faecalis}

Agmatine has been reported to act as an anti-proliferative agent in several non-intestinal mammalian cell models [41]. Since high induction concentrations were tested in the present work, assays were performed to see whether these affected bacterial viability.

Table 1 Oligonucleotides used

\begin{tabular}{|c|c|c|}
\hline Primer & Function & Sequence ( $5^{\prime}$ to $\left.3^{\prime}\right)$ \\
\hline $\operatorname{aguAq} F$ & aguA expression analysis (F) & TTGTGCCGCTTCATAAAATGG \\
\hline $\operatorname{aguAq} R$ & aguA expression analysis (R) & CACCTGGTGAAGTGGCTTGTATT \\
\hline aguRa $F$ & aguR expression analysis (F) & CGGGTTCATCTGATTGATTTTCTTC \\
\hline $\operatorname{aguRq} R$ & aguR expression analysis ( $R$ ) & CGTGATTTCCTCTGTCGGTTCTT \\
\hline recA $F$ & recA internal control (F) & CAAGGCTTAGAGATTGCCGATG \\
\hline recA $R$ & recA internal control $(\mathrm{R})$ & ACGAGGAACTAACGCAGCAAC \\
\hline EFV583-tufF & tuf internal control (F) & CAGGACATGCGGACTACGTTAA \\
\hline EFV583-tufR & tuf internal control (R) & TAGGACCATCAGCAGCAGAAAC \\
\hline AguR-EntBglll & Cloning $\mathrm{P}_{\text {aguR }}$-AguR-P $\mathrm{P}_{\text {aguB }}$ cassette ( $\mathrm{F}$ ) & CCCCAGATCT TTAAAAAGAAACAAGGTGGTGGCCG \\
\hline AguR EntNco & Cloning PaguR-AguR-P aguB cassette (R) & CCCCATGG TGTGTTCCTCCTAAAAGTTGTTITG \\
\hline Expvfor1 & Insertion of His-tag (F) & CACACACACCCATGGCTAATCGACTGCAGGAAAATTTATACTTCCAAGGTC \\
\hline Expvrev1 & Insertion of His-tag (R) & CTATCAATCAAAGCAACACGTG \\
\hline GFF1 & Cloning of GFP (F) & CACACACACCCATGGAATTCAGTAAGGGAGAAGAACTTTC \\
\hline GfR1 & Cloning of GFP (R) & CACACACACCTGCAG ACTAGTTTTGTAGAGCTCATCCATGC \\
\hline
\end{tabular}

$\mathrm{F}$, forward; $\mathrm{R}$, reverse; $\mathrm{P}_{\text {aguR }}$, aguR promoter; $\mathrm{P}_{\text {aguB }}$, aguB promoter; recA, recombinase $\mathrm{A}$; tuf, elongation factor $\mathrm{Tu}$. 

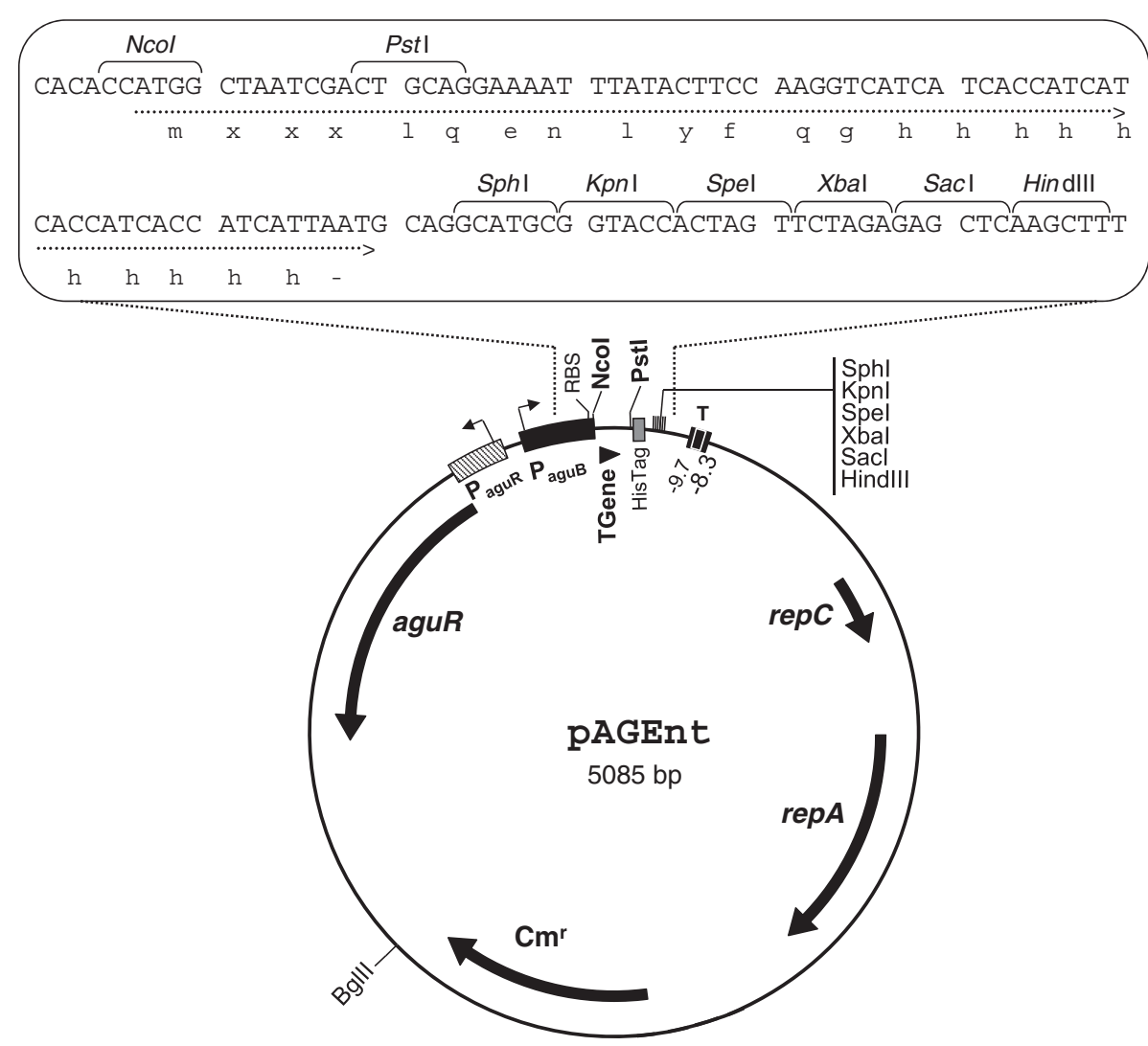

Figure 3 Genetic map of the expression vector pAGEnt and zoom-in of the expression cassette. repC and repA, replication genes; $\mathrm{cm}^{\mathrm{r}}$, chloramphenicol resistance gene; aguR, gene encoding the regulatory protein AguR; $\mathrm{P}_{\text {aguR, }}$ aguR promoter; RBS, ribosome binding site; T, transcription terminator; $\mathrm{P}_{\text {aguB, }}$ aguB agmatine-inducible promoter; TGene, open reading frame for target gene of interest; His-tag; C-terminal histidine tag. Representative restriction sites are indicated.

A

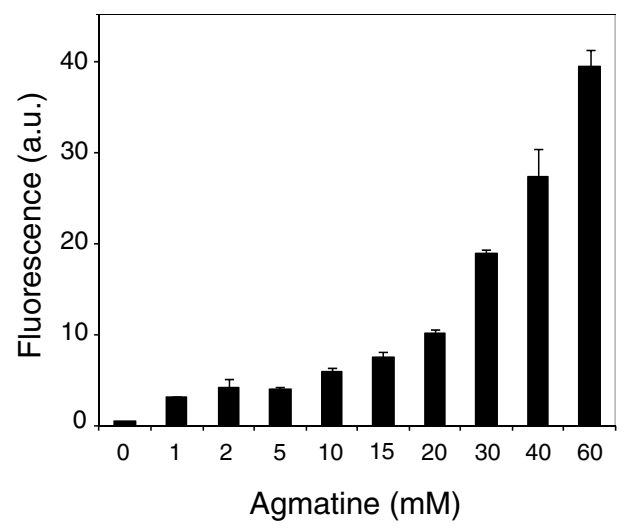

B

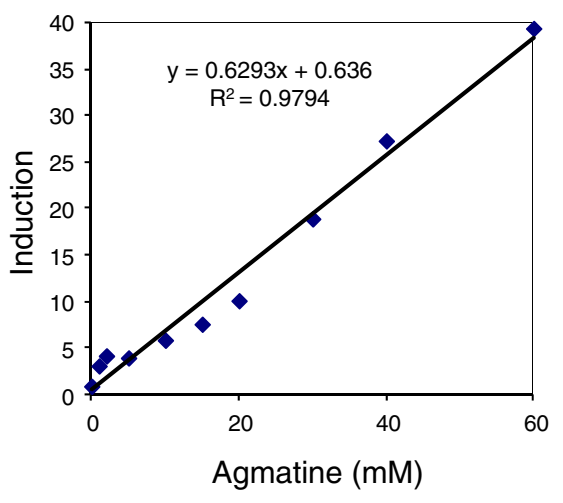

Figure 4 Sensitivity of the aguR/P ${ }_{a g u B}$ expression system to the inducer. A. Induction strength of gfp in E. faecalis V583 cultures containing pAGEnt-GFP under induction with a range of agmatine concentrations. Cultures harbouring the empty vector pAGEnt, or the vector pAGEnt-GFP with no agmatine present, were carried in parallel as negative controls. Error bars: mean standard deviation of three independent experiments. B. Correlation between inducer concentration $(\mathrm{mM})$ and reporter fluorescence (arbitrary units). 
E. faecalis cultures were grown in liquid GM17 supplemented with, 20, 40 or $60 \mathrm{mM}$ agmatine. After $24 \mathrm{~h}$ incubation, serial dilutions of each suspension were prepared and immediately plated to determine the number of viable bacteria (colony forming units per millilitre $[\mathrm{cfu} / \mathrm{ml}]$ ). Under all conditions, the average viable count ranged from 8.85 to $9.39 \log _{10}[\mathrm{cfu} / \mathrm{ml}]$ units; no significant differences were seen between the different agmatine-treated and untreated cultures (Figure 5). Thus, agmatine has no toxic effect on E. faecalis V583 cell viability after 24 hours of exposure, even at the high concentrations required for maximal induction.

\section{Discussion}

Some strains of E. faecalis have commercial uses, e.g., as probiotics that promote a beneficial gut environment [42] and in food fermentation processes [1,43-45]. Other strains, however, can pose food safety problems and yet others are a leading cause of opportunistic, hospitalacquired infections (including urinary tract infections, septicaemia, bacteraemia and endocarditis) [2]. The extensive use of antibiotics has resulted in the rise of multiresistant E. faecalis strains, making the treatment of infections difficult. The identification of traits that contribute to their pathogenicity is important in understanding the dual nature of this organism [24,46,47].

Despite scientific interest in this bacterium in recent years, the genetic toolbox and methodologies available

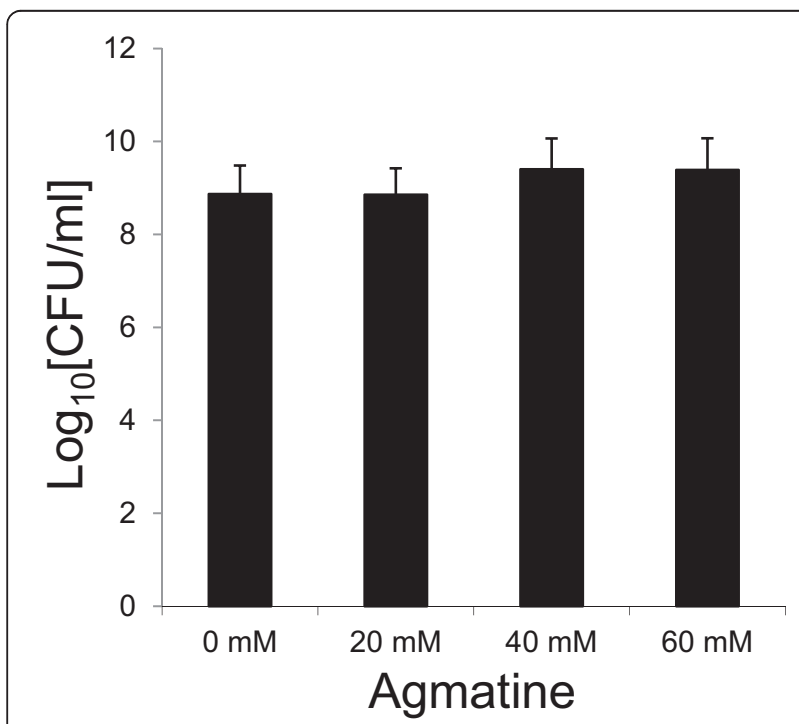

Figure 5 Susceptibility of E. faecalis V583 to agmatine. E. faecalis cultures were grown in liquid GM17 supplemented with $0 \mathrm{mM}, 20 \mathrm{mM}$, $40 \mathrm{mM}$ or $60 \mathrm{mM}$ agmatine. After $24 \mathrm{~h}$ of incubation, serial dilutions of the suspension were prepared and immediately plated to determine the number of viable bacteria $(\mathrm{cfu} / \mathrm{ml})$. The number of bacteria observed was within the range of 30 to 300 cfu per plate. Error bars represent standard deviation of three independent experiments. for overexpressing genes of interest are more limited than for some other microorganisms [48]. Although heterologous gene expression in an E. coli background is the most common method of producing recombinant proteins from other bacteria, autologous gene expression is an alternative when heterologous expression has failed [49]. Availability of appropriate expression vectors for E. faecalis becomes essential to express cloned genes efficiently, to study regulatory proteins, or to carry genetic complementation studies [50]. A number of expression systems for Enterococcus are available. Probably the best known controllable expression system for Gram-positive bacteria is based on the autoregulatory properties of nisin biosynthesis in L. lactis [38,39,51,52]. The system can be used in a wide range of genera including Lactococcus, Streptococcus, Enterococcus, Leuconostoc and Lactobacillus [53]. However, when used in Enterococcus, the regulatory genes nisR and nisK need to be supplied in trans. Similarly, the enterocin regulatory system for controlling the expression of heterologous genes in Enterococcus requires the regulator- and kinase-encoding genes $e n t R$ and $e n t K$ be expressed in trans [32]. In order to tackle this disadvantage, the NICE system was optimised to be used in Enterococcus as a single-plasmid expression vector [34]. Other inducible expression vectors for $E$. faecalis are available: the rhamnose-inducible system [35] and the recently described one that is under control of the pheromone cCF10 [54]. The present work describes an alternative system for controlled gene expression in E. faecalis using a single-plasmid expression system.

The present results show putrescine accumulation by E. faecalis V583 to be strictly agmatine-dependent. They also show that aguR gene expression is not modified by an increase in agmatine concentration of the culture medium, whereas aguBDAC gene expression is significantly upregulated by agmatine concentrations of over $0.25 \mathrm{mM}$. The suitability of the aguR/P $\mathrm{P}_{a g u B}$ system (the regulatory part of the AGDI system of E. faecalis V583) as an agmatine-induced gene expression system was therefore explored. An expression vector combining the $a g u R$ activator gene and the $a g u B$ promoter, followed by convenient cloning sites for introducing the gene of interest, was constructed. An important feature of the developed pAGEnt system is the addition of a histidine tag, which makes the vector an option for protein purification purposes. By cloning the target gene into the NcoI-PstI sites, the gene is inserted into the correct frame and fused to the His-tag. This His-tag was obtained from expression vectors previously shown to perform efficiently when used in protein overproduction, immunodetection and purification settings $[40,55]$.

This expression system was assessed by expressing the reporter gene $g f p$ (which codes for green fluorescent protein). 
Very strong fluorescence induction (40 arbitrary units compared to 0 in uninduced cells) was seen in the presence of $60 \mathrm{mM}$ agmatine. It should be noted that agmatine concentrations of $60 \mathrm{mM}$ are within the range associated with no toxic effect in Enterococcus. A potential benefit of having an expression system based on $a g u R /$ $\mathrm{P}_{\text {aguB }}$ is that gene expression can be finely controlled upon the addition of appropriate concentrations of agmatine. Agmatine is an intermediate in polyamine biosynthesis, and ubiquitous in living cells. However, it is normally present only in trace amounts - tissue concentrations are usually below $1 \mu \mathrm{M}$ [56]. It should also be noted that this system requires the expression of no additional proteins supplied in trans.

The present results clearly show that this system can effectively control the expression of genes in response to non-toxic agmatine in E. faecalis. This could be a useful tool for the overexpression of proteins in this species, and expands the toolbox available to use with it. Moreover, this system may be active in other Enterococcus species and perhaps in other Gram-positive hosts (as the NICE system may be used), although this needs to be confirmed.

\section{Conclusions}

The described agmatine-inducible system represents an attractive means for the overproduction and purification of recombinant proteins in E. faecalis. The present work describes the construction of an $E$. faecalis aguR $/ \mathrm{P}_{a g u B}$ controlled expression system and demonstrates its potential as a means of overproducing recombinant proteins. This system was assessed by expressing the reporter gene $g f p$, and very strong fluorescence was induced in the presence of $60 \mathrm{mM}$ agmatine (40 arbitrary units compared to 0 in uninduced cells). The potential benefit of this system is that gene expression can be finely controlled by the addition of appropriate concentrations of agmatine. The addition of a histidine tag to the pAGEnt vector renders the system suitable for protein purification purposes.

\section{Methods}

\section{Bacterial strains and growth conditions}

L. lactis NZ9000 was grown at $30^{\circ} \mathrm{C}$ in M17 medium (Oxoid, Basingstoke, United Kingdom) supplemented with $30 \mathrm{mM}$ glucose. E. faecalis V583 was grown at $37^{\circ} \mathrm{C}$ in M17 medium (Oxoid, Basingstoke, United Kingdom) supplemented with $30 \mathrm{mM}$ glucose (GM17). When required, the indicated concentration of agmatine (SigmaAldrich, St. Louis, MO) was added to the medium. Chloramphenicol $\left(5 \mu \mathrm{g} \mathrm{ml}^{-1}\right)$ was added as required.

\section{Analytical chromatography methods}

Cultures were centrifuged at $8000 \mathrm{~g}$ for $10 \mathrm{~min}$ and the resulting supernatants filtered through a $0.2 \mu \mathrm{m}$ Supor membrane (Pall, NY). Putrescine and agmatine concentrations were analysed by ultra-performance liquid chromatography $\left(\mathrm{UPLC}^{\mathrm{mm}}\right)$ using a Waters H-Class ACQUITY UPLC ${ }^{\mathrm{ms}}$ apparatus controlled by Empower 2.0 software and employing a UV-detection method based on derivatization with diethylethoxymethylene malonate (Sigma-Aldrich), as previously described [57].

\section{DNA manipulation procedures}

The procedures used for DNA manipulation and recombination were essentially those described by Sambrook et al. [58]. Table 1 lists the primer sequences used. Genetic constructs for Enterococcus were achieved using L. lactis NZ9000 as an intermediate host. Plasmid and total DNA of L. lactis and Enterococcus were isolated and transformed as previously described [59]. All plasmid constructs were verified by nucleotide sequencing at Macrogen Inc. (Seoul, Republic of Korea). All enzymes for DNA technology were used according to the manufacturer's specifications.

\section{RNA extraction}

Total RNA was extracted at $6 \mathrm{~h}$ of incubation using the TRI Reagent (Sigma) as previously described [21]. E. faecalis was grown in M17 or in M17 supplemented with $30 \mathrm{mM}$ glucose and $0,0.05,0.1,0.25,0.5,1,5,10$ or $20 \mathrm{mM}$ agmatine. The cells were then harvested by centrifugation and disrupted using glass beads (diameter up to $50 \mu \mathrm{m}$ ) in a Fast-Prep FP120 apparatus (Thermo SavantBIO101/Q-Biogen) at $4^{\circ} \mathrm{C}$ for $6 \times 30 \mathrm{~s}$ (power setting 6). The resulting samples were treated as recommended by the manufacturer. Purified RNAs were resuspended in RNAse-free water. After extraction, RNA samples were treated with DNase (Fermentas, Vilnius, Lithuania), as described by the manufacturer, to eliminate any genomic contamination. Total RNA concentrations were determined by UV spectrophotometry by measuring absorbance at $260 \mathrm{~nm}$ in a BioPhotometer (Eppendorf, Germany).

\section{Gene expression quantification by RT-qPCR}

Gene expression analysis was performed by reverse transcription-quantitative PCR (RT-qPCR) in a 7500 Fast Real-Time PCR System (Applied Biosystems, Carlsbad, $\mathrm{CA}$ ) using $\mathrm{SYBR}^{\oplus}$ Green PCR Master Mix (Applied Biosystems). After 2-fold dilution of the cDNA, $5 \mu$ l were added to $20 \mu \mathrm{l}$ of PCR mixture $(12.5 \mu \mathrm{l}$ of SYBR Green Supermix, $1 \mu \mathrm{L}$ of each primer at $7 \mu \mathrm{M}$, and $5.5 \mu \mathrm{l}$ of RNAse-free water). Amplifications were performed with specific primers (Table 1) designed with Primer Express software (Applied Biosystems); primers specific for elongation factor thermo-unstable $(t u f A)$ and recombinase A $(\operatorname{rec} A)$ genes were used as references. The cycling settings were those default-established by Applied Biosystems. For each condition, RT-qPCR analysis was performed on RNA purified from three independently grown cultures. 


\section{Green fluorescence measurements}

For whole-cell fluorescence measurements, equal amounts of cells were harvested, washed and subsequently resus-

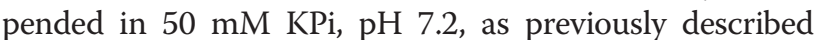
[40]. GFP emission was measured in a volume of $200 \mu \mathrm{l}$ of cells, using a Cary Eclipse fluorescence spectrophotometer (Varian Inc., Palo Alto, CA), at an excitation wavelength of $485 \mathrm{~nm}$ and an emission wavelength $530 \mathrm{~nm}$. For direct comparison, all the GFP fluorescence data were normalized to the same $A_{600}$. Background fluorescence levels were assessed by measuring non-fluorescent control cells, and these values subtracted.

\section{Statistical analysis}

Student $t$ tests were used to evaluate the consistency of the data.

\section{Abbreviations}

AGDI: Agmatine deiminase; GFP: Green fluorescence protein; VRE: Vancomycin resistant Enterococcus; RT-qPCR: Reverse transcription quantitative PCR; CFU: Colony forming units.

\section{Competing interests}

The authors declare that they have no competing interests.

\section{Authors' contributions}

DML designed, carried out some experiments and drafted the manuscript; $\mathrm{MP}$ and $\mathrm{BR}$ performed some experiments; $\mathrm{VL}, \mathrm{BdR}, \mathrm{MC}$ and MF participated in study design and helped to write the manuscript; MAA provided the general concept and supervised the work and the manuscript. All authors contributed to the discussion of the research and approved the final manuscript.

\section{Acknowledgements}

This work was funded by the Spanish Ministry of Economy and Competitiveness (AGL2013-45431-R). We acknowledge support of the publication fee by the CSIC Open Access Publication Support Initiative through its Unit of Information Resources for Research (URICI). We are also grateful to Bert Poolman for providing the GFP-derivative vectors. The authors thank Adrian Burton for linguistic assistance. Strain L. lactis NZ9000 and plasmid pNZ8048 were kindly provided by the NIZO Food Research. D.M.L. and B.d.R. were the beneficiaries of JAE DOC contracts (CSIC). M.P. is the recipient of an FPU fellowship from the Spanish Ministry of Education, Culture and Sport.

Received: 1 September 2014 Accepted: 18 November 2014 Published online: 04 December 2014

\section{References}

1. Centeno JA, Menendez S, Hermida M, Rodriguez-Otero JL: Effects of the addition of Enterococcus faecalis in Cebreiro cheese manufacture. Int J Food Microbiol 1999, 48:97-111.

2. Foulquié Moreno MR, Sarantinopoulos P, Tsakalidou E, De Vuyst L: The role and application of enterococci in food and health. Int J Food Microbiol 2006, 106(1):1-24.

3. Morandi S, Silvetti T, Brasca M: Biotechnological and safety characterization of Enterococcus lactis, a recently described species of dairy origin. Antonie Van Leeuwenhoek 2013, 103(1):239-249.

4. Aymerich T, Artigas MG, Garriga M, Monfort JM, Hugas M: Effect of sausage ingredients and additives on the production of enterocins $A$ and $B$ by Enterococcus faecium CTC492. Optimization of in vitro production and anti-listerial effect in dry fermented sausages. J Appl Microbiol 2000, 88:686-694

5. Leroy F, De VL: Bacteriocin production by Enterococcus faecium RZS C5 is cell density limited and occurs in the very early growth phase. Int J Food Microbiol 2002, 72(1-2):155-164.
6. De Vuyst L: Bacteriocins of Enterococcus. In Bacteriocins of Lactic Acid Bacteria. Edited by De Vuyst L, Vandamme EJ. London: Microbiology, Genetics and Applications, Blackie Academic \& Professional; 1994:511-513.

7. Giraffa G: Functionality of enterococci in dairy products. Int J Food Microbio 2003, 88(2-3):215-222.

8. Franz CM, van Belkum MJ, Holzapfel WH, Abriouel H, Gálvez A: Diversity of enterococcal bacteriocins and their grouping in a new classification scheme. FEMS Microbiol Rev 2007, 31:293-310.

9. Franz CM, Holzapfel W, Stiles ME: Enterococci at the crossroads of food safety? Int J Food Microbiol 1999, 47:1-24.

10. Giraffa G: Enterococcal bacteriocins: their potential as anti-Listeria factors in dairy technology. Food Microbiol 1995, 12:291-299.

11. Stiles ME, Holzapfel WH: Lactic acid bacteria of foods and their current taxonomy. Int J Food Microbiol 1997, 36:1-29.

12. ACNFP: MAFF Advisory Committee on Novel Foods and Processes: Report on Enterococcus faecium, strain K77D. 17 Smith Square, London SW1 3JR, United Kingdom: Ergon House c/o Nobel House; 1996.

13. Fritzenwanker M, Kuenne C, Billion A, Hain T, Zimmermann K, Goesmann A Chakraborty T, Domann E: Complete genome sequence of the probiotic Enterococcus faecalis Symbioflor 1 clone DSM 16431. Genome Announc 2013, 1(1):e00165-12

14. Commission E: List of the authorized additives in feedingstuffs published in application of Article $9 \mathrm{t}$ (b) of Council Directive 70/524/EEC concerning additives in feeding stuffs. Off J Eur Union 2004, C50

15. Lojanica M, Manojlović M, Jeremić D, Petronijević S: The effects of probiotic Enterococcus faecium DSM 7134 in the weaned pigs nutrition. Biotechnol Anim Husbandry 2010, 26(1-2):57-64.

16. Franz CM, Huch M, Abriouel H, Holzapfel W, Gálvez A: Enterococci as probiotics and their implications in food safety. Int J Food Microbiol 2011, 151(2):125-140.

17. Kreuzer S, Machnowska P, Aßmus J, Sieber M, Pieper R, Schmidt MF, Brockmann GA, Scharek-Tedin L, Johne R: Feeding of the probiotic bacterium Enterococcus faecium NCIMB 10415 differentially affects shedding of enteric viruses in pigs. Vet Res 2012, 43(1):58.

18. Bellomo G, Mangiagle A, Nicastro L, Frigerio G: A controlled double-blind study of SF68 strain as a new biological preparation for the treatment of diarrhoea in pediatrics. Curr Ther Res 1980, 28:927-936.

19. EFSA Panel on Additives and products or substances used in animal feed (FEEDAP): Scientific opinion on Cylactin ${ }^{\circledR}$ (Enterococcus faecium) for calves, lambs and kids for rearing and for fattening. EFSA J 2013, 11(2):3097-3110.

20. Fernández M, Linares DM, Álvarez MA: Sequencing of the tyrosine decarboxylase cluster of Lactococcus lactis IPLA 655 and the development of a PCR method for detecting tyrosine decarboxylating lactic acid bacteria. J Food Prot 2004, 67(11):2521-2529.

21. Linares DM, Fernández M, Martín MC, Álvarez MA: Tyramine biosynthesis in Enterococcus durans is transcriptionally regulated by the extracellular $\mathrm{pH}$ and tyrosine concentration. Microb Biotechnol 2009, 2(6):625-633.

22. Llácer JL, Polo LM, Tavárez S, Alarcón B, Hilario R, Rubio V: The gene cluster for agmatine catabolism of Enterococcus faecalis: study of recombinant putrescine transcarbamylase and agmatine deiminase and a snapshot of agmatine deiminase catalyzing its reaction. J Bacterio/ 2007, 189(4):1254-1265.

23. Ladero V, Fernández M, Calles-Enríquez M, Sánchez-Llana E, Cañedo E, Martín MC, Alvarez MA: Is the production of the biogenic amines tyramine and putrescine a species-level trait in enterococci? Food Microbiol 2012, 30(1):132-138.

24. Sundsfjord A, Willems R: Enterococcus research: recent developments and clinical challenges. Clin Microbiol Infect 2010, 16(6):525-526.

25. Arias CA, Murray BE: The rise of the Enterococcus: beyond vancomycin resistance. Nat Rev Microbio/ 2012, 10:266-278.

26. Abebe $W$, Endris M, Tiruneh M, Moges F: Prevalence of vancomycin resistant Enterococci and associated risk factors among clients with and without HIV in Northwest Ethiopia: a cross-sectional study. BMC Public Health 2014, 14:185-192.

27. Cetinkaya Y, Falk P, Mayhall CG: Vancomycin-resistant enterococci. Clin Microbiol Rev 2000, 13(4):686-707.

28. Lenz CA, Hew Ferstl CM, Vogel RF: Sub-lethal stress effects on virulence gene expression in Enterococcus faecalis. Food Microbiol 2010, 27(3):317-326

29. Linares DM, Fernández M, Del-Río B, Ladero V, Martin MC, Alvarez MA: The tyrosyl-tRNA synthetase like gene located in the tyramine biosynthesis 
cluster of Enterococcus durans is transcriptionally regulated by tyrosine concentration and extracellular pH. BMC Microbiol 2012, 12:23.

30. Ryan MP, McAuliffe O, Ross RP, Hill C: Heterologous expression of lacticin 3147 in Enterococcus faecalis: comparison of biological activity with cytolysin. Lett Appl Microbiol 2001, 32(2):71-77.

31. Hasman H, Aarestrup FM, Dalsgaard A, Guardabassi L: Heterologous expression of glycopeptide resistance vanHAX gene clusters from soil bacteria in Enterococcus faecalis. J Antimicrob Chemother 2006, 57(4):648-653.

32. Hickey RM, Twomey DP, Ross RP, Hill C: Potential of the enterocin regulatory system to control expression of heterologous genes in Enterococcus. J Appl Microbiol 2003, 95(2):390-397.

33. Eichenbaum Z, Federle MJ, Marra D, de Vos WM, Kuipers OP, Kleerebezem M, Scott JR: Use of the lactococcal nisA promoter to regulate gene expression in gram-positive bacteria: comparison of induction level and promoter strength. Appl Environ Microbiol 1998, 64(8):2763-2769.

34. Bryan EM, Bae T, Kleerebezem M, Dunny GM: Improved vectors for nisin-controlled expression in gram-positive bacteria. Plasmid 2000 44(2):183-190

35. Kristich CJ, Wells CL, Dunny GM: A eukaryotic-type Ser/Thr kinase in Enterococcus faecal is mediates antimicrobial resistance and intestinal persistence. Proc Natl Acad Sci U S A 2007, 104(9):3508-3513.

36. D'Urzo N, Martinelli M, Nenci C, Brettoni C, Telford JL, Maione D: High-level intracellular expression of heterologous proteins in Brevibacillus choshinensis SP3 under the control of a xylose inducible promoter. Microb Cell Fact 2013, 12:12.

37. Suárez C, Espariz M, Blancato VS, Magni C: Expression of the agmatine deiminase pathway in Enterococcus faecalis is activated by the AguR regulator and repressed by CcpA and PTS(Man) systems. PLoS One 2013, 8(10):e76170.

38. Kuipers OP, de Ruyter PG, Kleerebezem M, de Vos WM: Controlled overproduction of proteins by lactic acid bacteria. Trends Biotechnol 1997, 15:135-140.

39. Kuipers $O P$, de Ruyter $P G$, Keerebezem M, de Vos WM: Quorum sensing-controlled gene expression in lactic acid bacteria. J Biotechnol 1998, 64:15-21.

40. Linares DM, Geertsma ER, Poolman B: Evolved Lactococcus lactis strains for enhanced expression of recombinant membrane proteins. J Mol Biol 2010, 401(1):45-55.

41. Mayeur C, Veuillet G, Michaud M, Raul F, Blottière HM, Blachier F: Effects of agmatine accumulation in human colon carcinoma cells on polyamine metabolism, DNA synthesis and the cell cycle. Biochim Biophys Acta 2005, 1745(1):111-123

42. Hancock L, Perego M: Two-component signal transduction in Enterococcus faecalis. J Bacteriol 2002, 184(21):5819-5825.

43. Jiménez E, Ladero V, Chico I, Maldonado-Barragán A, López M, Martín V, Fernández L, Fernández M, Alvarez MA, Torres C, Rodríguez JM: Antibiotic resistance, virulence determinants and production of biogenic amines among enterococci from ovine, feline, canine, porcine and human milk. BMC Microbiol 2013, 13:288.

44. Gardini F, Bover-Cid S, Tofalo R, Belletti N, Gatto V, Suzzi G, Torriani S Modeling the aminogenic potential of Enterococcus faecalis EF37 in dry fermented sausages through chemical and molecular approaches. Appl Environ Microbiol 2008, 74:2740-2750.

45. Serio A, Paparella A, Chaves-Lopez C, Corsetti A, Suzzi G: Enterococcus populations in Pecorino Abruzzese cheese: biodiversity and safety aspects. J Food Prot 2007, 70:1561-1568.

46. Nallapareddy SR, Wenxiang H, Weinstock GM, Murray BE: Molecular characterization of a widespread, pathogenic, and antibiotic resistance-receptive Enterococcus faecalis lineage and dissemination of its putative pathogenicity island. J Bacteriol 2005, 187(16):5709-5718.

47. Abranches J, Martinez AR, Kajfasz JK, Chávez V, Garsin DA, Lemos JA: The molecular alarmone (p)ppGpp mediates stress responses, vancomycin tolerance, and virulence in Enterococcus faecalis. J Bacteriol 2009, 191(7):2248-2256.

48. Debroy S, van der Hoeven R, Singh KV, Gao P, Harvey BR, Murray BE, Garsin DA Development of a genomic site for gene integration and expression in Enterococcus faecalis. J Microbiol Methods 2012, 90(1):1-8.

49. Li H, O'Sullivan DJ: Heterologous expression of the Lactococcus lactis bacteriocin, nisin, in a dairy Enterococcus strain. Appl Environ Microbiol 2002, 68(7):3392-3400

50. Fujimoto S, lke Y: pAM401-Based shuttle vectors that enable overexpression of promoterless genes and one-step purification of tag fusion proteins directly from Enterococcus faecalis. Appl Environ Microbiol 2001, 67:1262-1267.

51. Kuipers OP, Beerthuyzen MM, de Ruyter PG, Luesink EJ, de Vos WM: Autoregulation of nisin biosynthesis in Lactococcus lactis by signal transduction. J Biological Chem 1995, 270:27299-27304.

52. Kuipers OP, Rollema HS, Beerthuyzen MM, Siezen RJ, de Vos WM: Protein engineering and biosynthesis of nisin and regulation of transcription of the structural nisA gene. Int Dairy J 1995, 5:785-795.

53. Kleerebezem M, Beerthuyzen MM, Vaughan EE, de Vos WM, Kuipers OP: Controlled gene expression systems for lactic acid bacteria: transferable nisin-inducible expression cassettes for Lactococcus, Leuconostoc, and Lactobacillus spp. Appl Environ Microbiol 1997, 63:4581-4584.

54. Borrero J, Chen Y, Dunny GM, Kaznessis YN: Modified lactic acid bacteria detect and inhibit multiresistant Enterococci. ACS Synth Biol 2014, Epub ahead of print.

55. Geertsma ER, Groeneveld M, Slotboom DJ, Poolman B: Quality control of overexpressed membrane proteins. Proc Natl Acad Sci U S A 2008, 105(15):5722-5727.

56. Piletz JE, Aricioglu F, Cheng JT, Fairbanks CA, Gilad VH, Haenisch B, Halaris A, Hong S, Lee JE, Li J, Liu P, Molderings GJ, Rodrigues AL, Satriano J, Seong GJ, Wilcox G, Wu N, Gilad GM: Agmatine: clinical applications after 100 years in translation. Drug Discov Today 2013, 18(17-18):880-893.

57. Redruello B, Ladero V, Cuesta I, Álvarez-Buylla JR, Martín MC, Fernández M, Alvarez MA: A fast, reliable, ultra high performance liquid chromatography method for the simultaneous determination of amino acids, biogenic amines and ammonium ions in cheese, using diethyl ethoxymethylenemalonate as a derivatising agent. Food Chem 2013, 139(1-4):1029-1035.

58. Sambrook JD, Russell D: Molecular Cloning a Laboratory Manual. Cold Spring Harbor, NY: Cold Spring Harbor Laboratory; 2001

59. de Vos WM, Vos P, Dehaard H, Boerritger I: Cloning and expression of the Lactococcus lactis ssp cremoris SK11 gene encoding an extracellular serine proteinase. Gene 1989, 85:169-176.

doi:10.1186/s12934-014-0169-1

Cite this article as: Linares et al:: An agmatine-inducible system for the expression of recombinant proteins in Enterococcus faecalis. Microbial Cell Factories 2014 13:169.

\section{Submit your next manuscript to BioMed Central and take full advantage of:}

- Convenient online submission

- Thorough peer review

- No space constraints or color figure charges

- Immediate publication on acceptance

- Inclusion in PubMed, CAS, Scopus and Google Scholar

- Research which is freely available for redistribution 